\title{
Computerized Tomography Score for the Assessment of Multiple Organ Failure and Determining Severity of Pancreatitis: Key Principles for the Assessment of Affected Organs
}

\author{
Madina Ermekova*, Makash Aliyakparov, Kayrat Shakeev, Gulfayruz Zholdybayeva \\ Department of Surgical Conditions, Karaganda Medical University, Karaganda, Kazakhstan
}

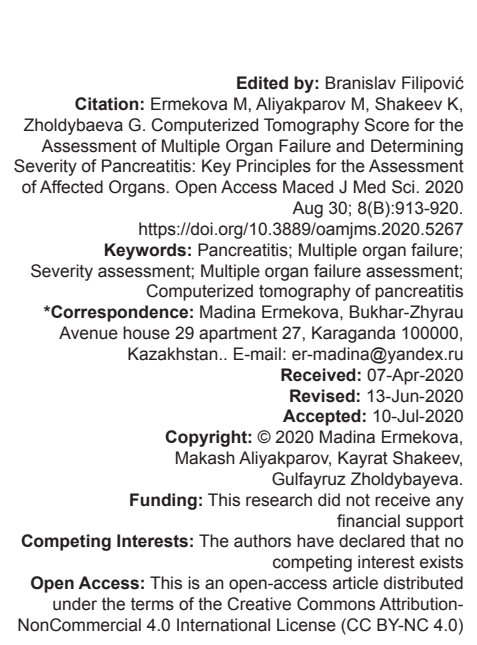

\section{Introduction}

Timely and correct assessment of acute pancreatitis (AP) severity increases the likelihood of appropriate treatment and improves predicted outcome [1], [2], [3], [4], [5]. According to the guidelines for the treatment of pancreatitis, one of the criteria of pancreatitis severity is organ failure that remains within $24 \mathrm{~h}$ after admission [3]. All clinical recommendations over the past 6 years specify the requirement to assess patient's condition severity immediately after diagnosing and to carry out reassessment over time, especially within $48 \mathrm{~h}$ [6], [7], [8].

All clinical recommendations for the assessment of expected response to the treatment of AP in clinical practice employ two approaches that include using various integrated score and examination of individual laboratory findings [9], [10], [11], [12].

There is a great number of surgical assessment scores such as Ranson APACHE-II, MODS 2, and Glasgow that enable accurate determining severity of patient's condition, likelihood of fatal outcome, and intensity of biochemical changes [12], [13], [14], [15], [16], [17].

The range of diagnostic radiology methods used for imaging of pathological changes of the pancreas is quite wide and choice of a method depends on examination purpose, clinical symptoms, time of symptom onset, and on laboratory testing data. However to this day, the majority of researchers prefer computerized tomography (CT) in various clinical situations [17], [18], [19], [20], [21]. According to data 
of the American College of Gastroenterology from 2013 and Japanese recommendations on treatment of AP from 2015 , CT is generally agreed to be the golden standard in diagnosing pancreatitis as it enables assessment of condition of the pancreas and the surrounding areas. For this reason, alongside the integrated surgical scores based on clinical and laboratory assessment, the scores based on data obtained through CT examinations received global acceptance [17], [18], [19], [20], [21].

At present, the most frequent use is made of such radiologic scores as CT severity index (CTSI), modified CTSI, pancreas size index, extrapancreatic point (EP), assessment of extrapancreatic inflammation on CT (EPIC - is assessed by presence of ascites, pleuritis, and retroperitoneal and mesenteric edema), assessment of mesenteric edema and peritoneal fluid (MOP - assessment of presence or absence of peritoneal edema and/or mesenteric fluid), and the Balthazar score [22], [23], [24]. Altogether it was pointed out that regardless of a selected method, CT demonstrates a very high accuracy among assessment scores for severity level prediction. There have not been any statistically significant differences between predictive accuracy of CT and the clinical assessment scores [25], [26], [27], [28], [29], [30].

However, we have noted that estimation scores based on data obtained through CT examinations used in case of pancreatitis do not account entirely for condition of the surrounding organs due to the limitation of the area of interest by the pancreas only and the surrounding tissues within a short distance from the pancreas [24], [25], [26], [27], [28], [29], [30], [31], [32], [33], [34], [35]. It is acknowledged by many researchers that the capacities of computerized diagnosing are not used to the full extent [17], [24].

As many other researchers, we have come to the conclusion that the existing surgical systems of assessment scores are quite effective in prediction of organ failure under the conditions of AP. However, they are cumbersome in use and, therefore, have limitations in clinical application. We believe that there is still a need in the development of new approaches, which is acknowledged by scientists from different countries [18], [24].

Since it is CT that is a golden standard in diagnosing conditions of the pancreas and it covers a sufficient examination area enabling to assess condition of almost all large organs and systems, we have proposed a way informative value of this method by means of more detailed examination of these organs and systems in the course of analysis of a standard CT investigation. The investigation's goal was to identify CT signs of organ changes in patients whose test results indicate organ failure. It was proposed to divide changes identified during $\mathrm{CT}$ examination in accordance with pancreatitis classification having three severity levels and to determine the extent to which CT presentation corresponds to clinical assessment of patient's condition. Hence, performance of a standard abdominal CT scanning in addition to the assessment of any changes in the pancreas can also identify presence of any single and multiple organ changes caused by AP, which will enable timely correction of severity level and treatment of this disease.

\section{Materials and Methods}

A randomized study was carried out at the premises of two regional clinics and one private clinic of the city of Karaganda during 2017-2019 years. We examined 314 patients with suspected or clinically confirmed pancreatitis who were sent for CT scanning of abdominal organs. The inclusion criteria were as follows: Patients of both genders at least 18 years old who were admitted to an inpatient hospital through emergency room diagnosed with AP during the $1^{\text {st }}$ stage of the disease. The criteria for exclusion from the study were as follows: Medical history with diabetes mellitus and other endocrine, autoimmune, contagious, oncological diseases, existing severe concomitant cardiovascular morbidity, cardiac insufficiency, and medical history with allergic reactions. Clinical and laboratory data were taken from patient medical records and confirmed existence of a single or several organ failure. Respiratory failure was identified as $\mathrm{PaO} 2$ under $60 \mathrm{mmHg}$ or as a need in ventilatory care. Renal failure was identified by creatinine in serum if it exceeded $300 \mu \mathrm{mol} / \mathrm{l}$ or by drop of urine output below $500 \mathrm{ml} / 24 \mathrm{~h}$ or below $180 \mathrm{ml} / 8 \mathrm{~h}$ as well as the need in hemodialysis or peritoneal dialysis. Hepatic failure was identified by serum bilirubin level exceeding $100 \mu \mathrm{mol} / \mathrm{l}$ or by alkaline phosphatase level exceeding 3 times the upper limit of normal range.

All studies were performed using CT machines (Somatom Definition AS, Siemens) applying the standard CT conclusion for abdominal imaging. Then, images were processed and reconstructed in axial plane with $5 \mathrm{~mm}$ slice thickness. All CT data obtained in our institute were reviewed independent of one another at two work stations with the aid of Syngo Imaging software, version VB36A, Siemens Medical Solutions.

Two radiation therapists (the first author and the second author), having over 3 years of experience in abdominal radiology, carried out an independent check of all CT images without knowing any patient specifics and their clinical outcome. A result was considered to be final when both radiation therapists, independent of each other, reached the same conclusion with regard to the presence of alterations and process severity. When CT results were controversial, the final result was achieved based on consensus. All patients had the Balthazar score points calculated and recorded based on review of CT images.

Statistical processing of the material was carried out using the software tools STATISTICA v. 6.0. After preparing the data file, which consisted of finding 
and fixing errors, an array in the form of $a^{*}$.xls file was imported into the STATISTICA package with conversion to an STA file and then processed in accordance with the task. The normality of the distribution was checked using the Shapiro-Wilks test. The hypothesis of statistical homogeneity of the two samples was tested using the Student's and Pearson $\chi^{2}$ criteria. Univariate analysis of variance was used to identify predictors of multiple organ failure. All patients with pancreatitis revealed a statistically significant relationship between the underlying disease and the affected organ system. In particular, in patients with a mild disease severity, damage to the gallbladder and perinephric fiber was noted $\left(\chi^{2}=5.1 ; p<0.05\right.$ and $\chi^{2}$ $=5.5 ; p<0.05$, respectively), and in patients with a severe degree, pancreatitis was the leading in the structure of multiple organ failure syndrome of portal hypertension $\left(\chi^{2}=3.4 ; p<0.05\right)$. Based on the results of the study, we identified signs characteristic of pancreatitis of varying severity, determined by CT scan of the abdominal cavity with contrast. Of these signs, by means of statistical selection, we determined those that meet the Pearson's reliability criterion $\chi^{2}$.

\section{Discussion and Results}

Out of 314 patients, 100 patients were selected diagnosed with pancreatitis confirmed by changes demonstrated by the laboratory test results. Of those, 24 patients $(24.0 \%)$ revealed presence of multiple organ failure (maximum of 5 organ systems), 46 patients revealed a single organ failure. Development of early organ failure accompanied $82 \%$ of cases of severe pancreatitis and considerably aggravated predicted outcome and course of severe AP. Complications in two body systems were identified in $60 \%$ of observations; complications in more than 2 systems were in $40 \%$ of observations. Early organ failure during the $1^{\text {st }}$ stage of the disease was the cause of two fatal outcomes, which amounted to $4.65 \%$ of the total number of persons with severe AP. In this study, we have established that frequency of organ failure rises with greater extent of necrosis (Table 1).

Table 1: Organ failure and multiple organ failure. Patient distribution per severity level and failure of organs and systems

\begin{tabular}{|c|c|c|c|}
\hline Without organ failure & & 30 & \\
\hline Organ failure & & 46 & \\
\hline Multiple organ failure & & 24 & \\
\hline Affected organ & Total & Moderate level & Severe level \\
\hline Lungs & 41 & 21 & 20 \\
\hline Liver & 33 & 11 & 22 \\
\hline GIT & 21 & 9 & 12 \\
\hline Kidneys & 9 & 5 & 4 \\
\hline Vessels & 7 & 4 & 3 \\
\hline
\end{tabular}

From among the specified types of multiple organ failure, we factored in five system changes in which can be visualized by employing contrast-enhanced abdominal CT. One of the most frequent complications is acute respiratory failure [36]. Pulmonary dysfunction is considered the most commonly encountered and according to various researchers accounts for $30 \%$ of patients [37]. Its development is caused by progressing intoxication that involves the respiratory center into the process. The greater activity of pancreatic enzymes cause pleural-pulmonary complications as wet pleuritis, atelectasis, pneumonia, pulmonary edema [38]. In our study, among the patients suffering a single organ failure, 21 patients revealed pulmonary failure signs of which can be identified by means of CT image review in lung window. When dealing with a mild case of pancreatitis, minor changes were identified manifested as increased pulmonary vascularity. As a more severe condition developed, CT identified signs of pneumatization disorder (in 16 cases) (Figure 1).

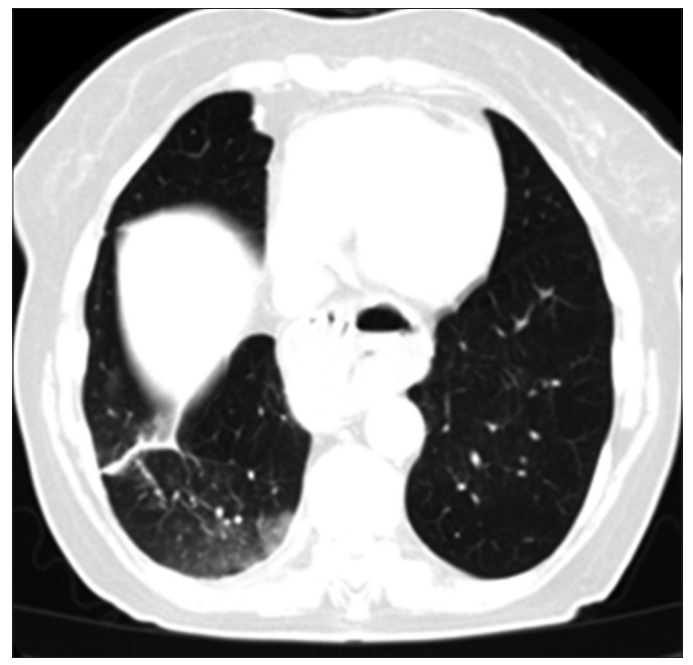

Figure 1: Patient $K$ with medium severity acute pancreatitis. Disorder of pneumatization of lung tissue in the form of ground-glass opacity

According to the data of the clinical study 2, patients with pancreonecrosis manifested pleural fluid, saturation disorder, and their condition was assessed as severe. This was confirmed during CT examination where in addition to wet pleuritis, signs of bronchopneumonic infiltration were identified as well (Figure 2).

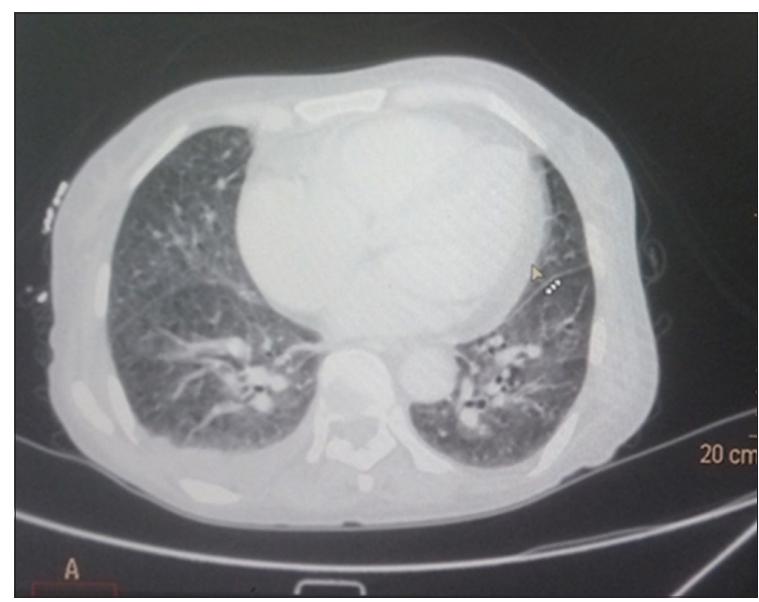

Figure 2: Patient $S$ with pancreonecrosis. One can identify wet pleuritis on the right, bronchopneumonic infiltration, signs of congestion in both lungs

According to the study data, liver insufficiency develops in $20-75 \%$ of cases of acute destructive pancreatitis, which significantly aggravates morbidity [39], [40]. The leading cause of functional 
changes in liver in case of AP is the developing deep microcirculatory abnormalities, degenerative-dystrophic changes of hepatocytes, and decompensation of detoxification mechanisms. In $72.7 \%$ of observations, pancreatitis is accompanied by the development of total extrahepatic portal hypertension which is confirmed by presence of both portoportal and portosystemic shunts (Figure 3).

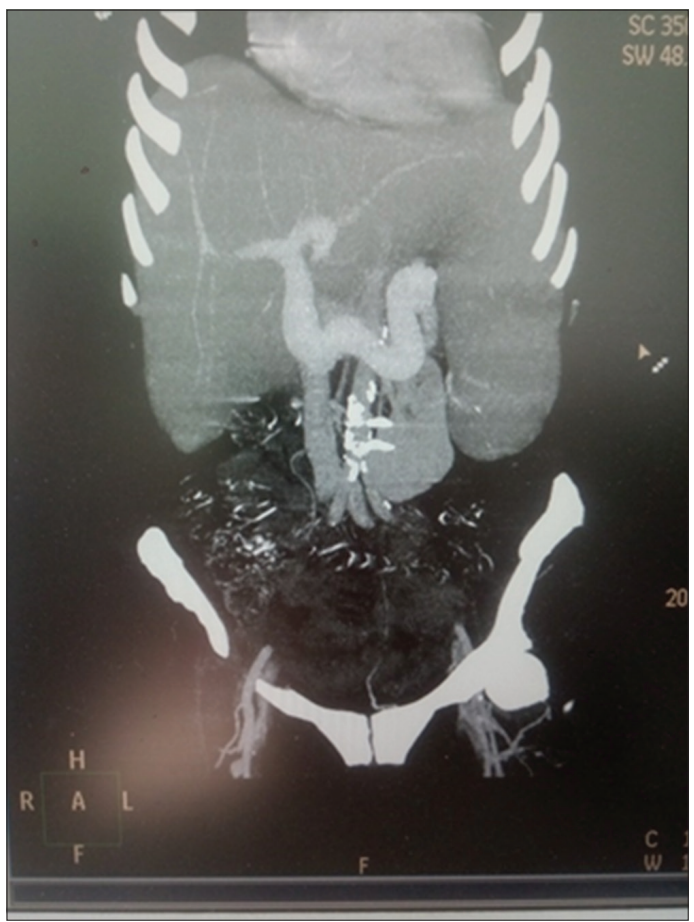

Figure 3: Patient $S$ with acute pancreatitis. There are signs of portal hypertension - phlebectasia of portal and splenic vein

According to our studies, if patients already having liver diseases are excluded from the area of interest, then they will be identified only in 33 cases most frequently manifested as signs of portal hypertension in patients with pancreatitis of medium severity level.

Damage or dysfunction of intestines and gastrointestinal tract is one of the routes of multiple organ failure development, formidable, and understudied complication of AP. These are observed, as different authors have different data, in $5-10 \%$ of patients on average [41], [42], [43]. Blood loss during $\mathrm{AP}$ aggravates hypovolemia and organ hypoxia and contributes to the development of further destructive changes in the pancreas.

The most frequent location of bleeding acute ulcers and erosions is stomach. Other locations of the pathological process are usually combined with stomach; rarely, isolated extragastric damage of the gastrointestinal tract is encountered [41].

The main in pathogenesis of acute erosions and ulcers, progression of early ulcerous-necrotic changes in the mucous lining, and hence emergence of acute bleeding is disruption of microcirculation in the digestive tract walls. In such a case, an important role is played by disruption of portal blood flow, which leads to hypoxia of the digestive tract's mucous lining (more frequently stomach' lining), impairment of its resistance, and development of dystrophic processes in it [42]

The next cause of ulcerous damage is increased aggressive factors in the stomach. As known, AP is accompanied by enhanced release of kinins, permanent impairment of gastric secretion with hypergastrinemia manifested in hypersecretion, and continuous acidogenesis. An important cause is flatulent distention, pylorus dysfunction, and duodenogastric reflux. Alongside this, there is a decrement of the mucous lining protective factors (reduced emission of gastric mucin, secretion of the pancreas bicarbonates, and consequences of using hormonal preparations) [43].

Enteral insufficiency syndrome may be included with other GIT damages. Before everything else, the motor function of the stomach is disrupted with the development of flatulent distention (Figure 4).

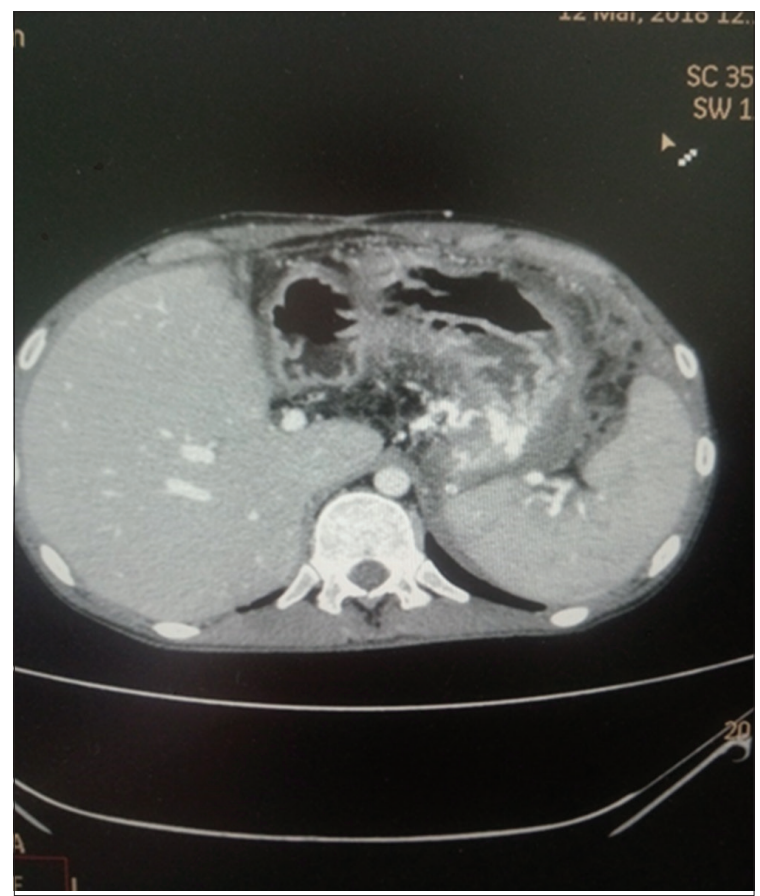

Figure 4: Patient Zh with medium severity acute pancreatitis. Contrastenhanced abdominal computerized tomography. Inhomogeneity and thickening of the stomach walls, dysperistalsis

It is not always possible to clearly differentiate severity levels of gastrointestinal loss because presence of violent peristalsis and dyspeptic processes persists at severe levels of pancreatitis and often prevents assessment of occurring changes.

We were able in our study to differentiate changes in GIT as moderate thickening of intestinal walls, lumen dilation in case of mile damage, inhomogeneity of intestine wall structure, dysperistalsis as manifestations of medium severity level, and indications of intestinal obstruction, infiltration of circumintestinal fat tissue in severe situations.

Among identified organ lesions, the fourth place was given to renal failure that we diagnosed with nine patients. Close relation of kidney failure pathogenesis 
with pancreatitis is explained by common blood supply and nearly the same anatomic substrate. It is not infrequent for acute renal failure to occur during AP and less often during chronic pancreatitis, which is due to a sudden reduction in effective renal blood flow [44]. This happens due to a combination of several factors: Spastic stricture of renal microvasculature (endothelium dysfunction), microthrombosis, as well as fluid loss and redistribution (sequestration). All of these phenomena stem from systemic effects of pancreatitis and attest to the respective stage of the adaptive process [45].

Results of laboratory testing: Elevated urea nitrogen and creatinine levels in serum reflect reduced removal of nitrogenous waste. The multicenter study that was carried out by Ke et al. [10] revealed that acute renal failure occurs in almost $70 \%$ of cases of severe AP with patients who were admitted to ICU.

We adopted the early indicators of changes to be decrease in density of parenchyma and thickening of Gerota's fascia that could be identified in three patients with mild AP.

Further changes on CT were identified as changes in size and hydronephrosis in a time of marked severity of the patient's condition. Use of contrast agent was contraindicative, but even by means of examinations performed without contrasting, we could identify marked changes of parenchyma (Figure 5).

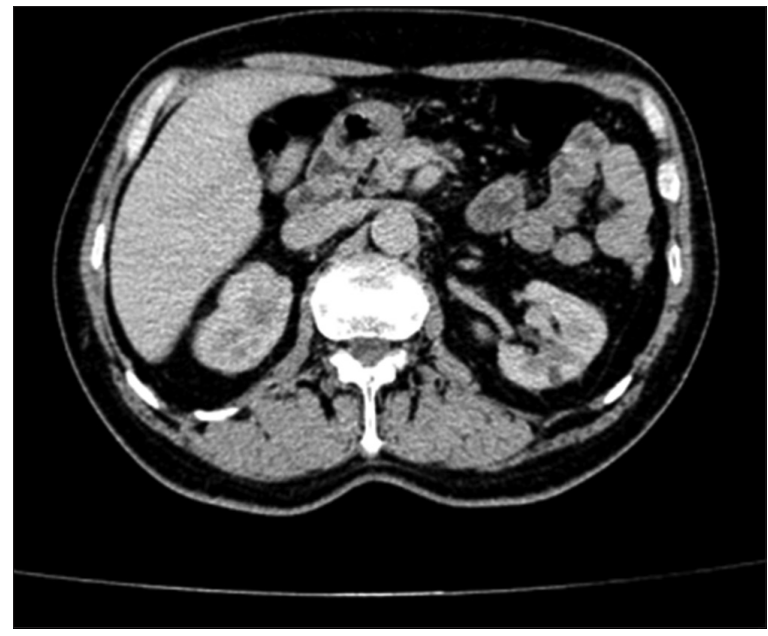

Figure 5: Patient O. Medium severity acute pancreatitis with signs of hydronephrosis.

Of no small importance in assessment of multiple organ failure is cardiac involvement, but during our study, analysis of cardiac norm and pathology showed excessive data spread, which made data unreliable to be used for assessment. However, it seems possible to assess on CT images changes of large vessels that enable indirect assessment of the patient's condition severity.

According to literary sources, AP can lead to various vascular events in $5 \%$ of cases including venous and arterial conditions [44], [45], [46]. Among venous complications frequently encountered are porto-spleno-mesenteric venous thrombosis that often includes thrombosis in the portal vein trunk, in the splenic vein, or even the superior mesenteric vein. This can lead to gastric or esophageal variceal bleeding, to ascites, portal hypertension, and hepatic failure [45].

Another consequence of local inflammation is damage of vessels in the pancreas that manifests itself by endothelial activation and endothelium damage, by higher vascular permeability, coagulation activation, and increased leukocyte rolling, adhesion, and transmigration into the pancreas tissue [46].

In our study, we identified vascular abnormalities in seven patients. Predominantly, those were in the form of dilation, thrombosis, and emergence of pathological anastomoses (Figure 6).

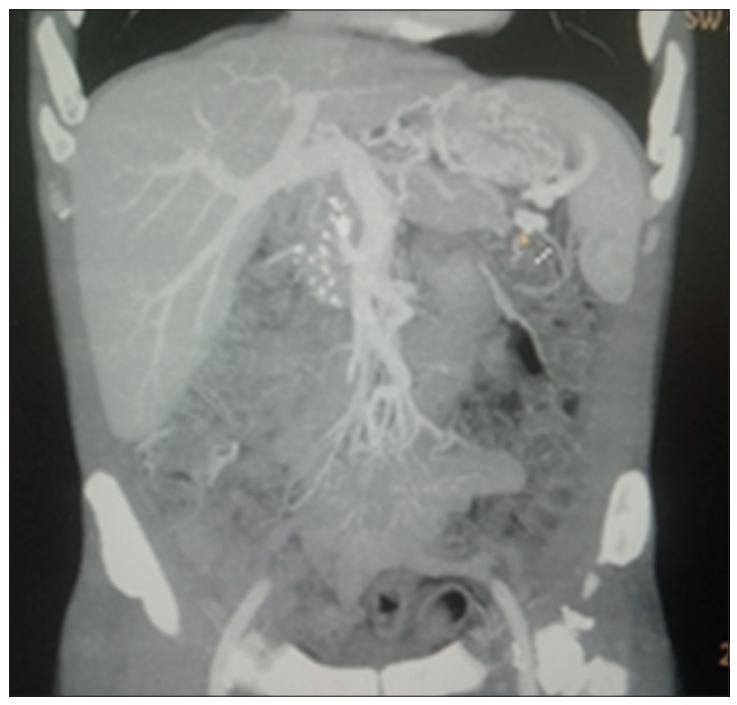

Figure 6: Patient $V$ with moderate severity acute pancreatitis. Splenorenal anastomoses

Based on review of CT images, all patients had the Balthazar score points calculated and recorded. Ranson and Apache condition severity assessment scores were also calculated for each patient.

Based on the obtained data, we developed and proposed for use our condition severity assessment score.

The score also includes information about changes in condition of the pancreas itself according to the standard signs that correspond to the pancreas damage severity the best. On top of that, we took note of the fact that in determining severity level, it is not of small importance to consider the number of affected organs, which we could also reflect in the Table 2.

Further use of this score in review of CT examinations confirmed its applicability in clinical practice. We must admit that our study has a series of limitations. First, the study covered not very many people as it included only 100 patients. Second, we did our analysis only for the subgroup of patients with AP within consecutive group of patients who had CT scanning within $24 \mathrm{~h}$ after emergence of symptoms in the first 3 days after admission. Some patients with severe AP received treatment without $C T$ scanning, 
Table 2: Score for computerized tomography-based assessment of pancreatitis severity

\begin{tabular}{|c|c|c|c|c|c|}
\hline \multirow[t]{2}{*}{ Group No. } & \multirow{2}{*}{$\begin{array}{l}\text { Organ } \\
\text { system }\end{array}$} & \multicolumn{4}{|l|}{ Points } \\
\hline & & 0 & 1 & 2 & 3 \\
\hline 1 & Pancreas & $\begin{array}{l}\text { No } \\
\text { changes }\end{array}$ & $\begin{array}{l}\text { Inflammatory } \\
\text { changes of } \\
\text { pancreas }\end{array}$ & $\begin{array}{l}\text { Inflammatory } \\
\text { changes of } \\
\text { pancreas and } \\
\text { surrounding } \\
\text { tissues }\end{array}$ & $\begin{array}{l}\text { Areas of necrosis in } \\
\text { pancreas }\end{array}$ \\
\hline 2 & GIT & $\begin{array}{l}\text { No } \\
\text { changes }\end{array}$ & $\begin{array}{l}\text { Moderate } \\
\text { thickening } \\
\text { of intestinal } \\
\text { walls, lumen } \\
\text { dilation }\end{array}$ & $\begin{array}{l}\text { Inhomogeneity } \\
\text { in structure of } \\
\text { intestinal wall, } \\
\text { dysperistalsis }\end{array}$ & $\begin{array}{l}\text { Indications of } \\
\text { intestinal obstruction } \\
\text { and infiltration of } \\
\text { circumintestinal fat } \\
\text { tissue }\end{array}$ \\
\hline 3 & $\begin{array}{l}\text { Liver and } \\
\text { spleen }\end{array}$ & $\begin{array}{l}\text { No } \\
\text { changes }\end{array}$ & $\begin{array}{l}\text { Dilation of } \\
\text { common } \\
\text { bile duct } \\
\text { and distal } \\
\text { segments of } \\
\text { hepatic ducts }\end{array}$ & $\begin{array}{l}\text { Changes in } \\
\text { density (transient } \\
\text { difference in } \\
\text { liver density), } \\
\text { hepatomegalia, } \\
\text { splenomegaly }\end{array}$ & Ascites \\
\hline 4 & Lungs & $\begin{array}{l}\text { No } \\
\text { changes }\end{array}$ & $\begin{array}{l}\text { Prominence } \\
\text { of perihilar } \\
\text { markings }\end{array}$ & $\begin{array}{l}\text { Disorder of } \\
\text { pneumatization } \\
\text { (ground glass), } \\
\text { pleural effusion }\end{array}$ & $\begin{array}{l}\text { Bronchopneumonic } \\
\text { infiltration }\end{array}$ \\
\hline 5 & Kidneys & $\begin{array}{l}\text { No } \\
\text { changes }\end{array}$ & $\begin{array}{l}\text { Decreased } \\
\text { density of } \\
\text { parenchyma }\end{array}$ & $\begin{array}{l}\text { Change of } \\
\text { kidneys size }\end{array}$ & $\begin{array}{l}\text { Thinning of kidney } \\
\text { parenchyma and } \\
\text { hydronephrosis }\end{array}$ \\
\hline 6 & Vessels & $\begin{array}{l}\text { No } \\
\text { changes }\end{array}$ & $\begin{array}{l}\text { Changes of } \\
\text { one large } \\
\text { vessel } \\
\text { (dilation, } \\
\text { thrombosis) }\end{array}$ & $\begin{array}{l}\text { Dilation of } \\
\text { portal and } \\
\text { splenic veins, } \\
\text { mesenteric vein }\end{array}$ & $\begin{array}{l}\text { Emergence of } \\
\text { portosystemic } \\
\text { bypasses, unstable } \\
\text { anastomosis, } \\
\text { thrombosis }\end{array}$ \\
\hline 7 & $\begin{array}{l}\text { Number } \\
\text { of affected } \\
\text { systems }\end{array}$ & $\begin{array}{l}\text { Other } \\
\text { organs } \\
\text { not } \\
\text { affected }\end{array}$ & $\begin{array}{l}\text { One organ } \\
\text { affected }\end{array}$ & $\begin{array}{l}\text { Two organs } \\
\text { affected }\end{array}$ & $\begin{array}{l}\text { Three organs } \\
\text { affected }\end{array}$ \\
\hline
\end{tabular}

which possibly contributed to a lower death rate in our group. These limitations could introduce inaccuracy into results of our study.

\section{Conclusions}

Nonetheless, in concluding, we would like to point out that following the results of this study, we conclude a quite high potential of CT in assessment of organ abnormalities, and the developed score for CT-based assessment of pancreatitis severity can be used not only for identification but also for prediction of failure of various organs at the early stage of pancreatitis to a high accuracy as compared with the conventional CT-based systems for the assessment of condition of patients with pancreatitis. It can also be used to differentiate severity of organ failure and the number of affected organs.

\section{References}

1. Gurusamy KS, Debray TP, Rompianesi G. Prognostic models for predicting the severity and mortality in people with acute pancreatitis. Cochrane Database of Systematic Rev. 2018;5:CD013026. https://doi.org/10.1002/14651858.cd013026

2. Tenner S, Baillie J, DeWitt J, Vege SS; American College of Gastroenterology. American college of gastroenterology guideline: Management of acute pancreatitis. Am J
Gastroenterol. 2013;108:1400-15. https://doi.org/10.1038/ ajg.2013.218

PMid:23896955

3. McPherson SJ, O'Reilly DA, Sinclair MT, Smith N. The use of imaging in acute pancreatitis in United Kingdom hospitals: findings from a national quality of care study. $\mathrm{Br} J$ Radiol. 2017;90:20170224. https://doi.org/10.1259/bjr.20170224

PMid:28869389

4. Working Group IAP/APA Acute Pancreatitis Guidelines. IAP/ APA evidence based guidelines for the management of acute pancreatitis. Pancreatology. 2013;13:e1-15. https://doi. org/10.1016/j.pan.2013.07.063

PMid:24054878

5. Chronic Pancreatitis Treatment Protocol for RK. RCHD (Republican Center for Health Development of the Ministry of Health of the Republic of Kazakhstan) Version: Clinical Protocols of the Ministry of Health of the Republic of Kazakhstan 2017 Approved by the Joint Commission for the Quality of Medical Services of the Ministry of Health of the Republic of Kazakhstan dated December 14, 2017 Protocol No. 35. Almaty, Kazakhstan: Ministry of Health of the Republic of Kazakhstan; 2017. https:// doi.org/10.20953/1817-7646-2017-5-73-77

6. Acute Pancreatitis of the RCCH (Republican Center for Health Development of the Ministry of Health of the Republic of Kazakhstan) Version: Clinical protocols of the Ministry of Health of the Republic of Kazakhstan 2018 ICD-10: Acute Pancreatitis (K85) Approved by the Joint Commission on the Quality of Medical Services of the Ministry of Health of the Republic of Kazakhstan dated March 29, 2019 Protocol No. 60. Almaty, Kazakhstan: Ministry of Health of the Republic of Kazakhstan; 2019. https://doi.org/10.20953/1817-7646-2017-5-73-77

7. Podoluzhny VI. Acute pancreatitis: Current understanding of the etiology, pathogenesis, diagnosis and treatment. Fundam Clin Med. 2017;2(4):62-71.

8. Ermekova MA, Aliyakparov MT, Cheremisin VM, Shakeev KT, Kamyshanskaya IG. The possibilities of radiation methods in the diagnosis and prognosis of acute pancreatitis and its complications. Med Ecol. 2019;1(90):80-92.

9. Ushakov AA, Ovchinnikov VI, Babushkin DA. Prognostic significance of indicators for assessing the severity of acute pancreatitis. Int J Appl Basic Res. 2016:4:721-3.

10. Ke L, Tong Z, Li W, Wu C, Li N, Windsor JA, et al. Predictors of critical acute pancreatitis: A prospective cohort study. Medicine. 2014;93:e108. https://doi.org/10.1097/md.0000000000000108 PMid:25380082

11. Leppäniemi A, Tolonen $M$, Tarasconi A, Segovia-Lohse $H$ Gamberini E, Kirkpatrick AW, et al. 2019 WSES guidelines for the management of severe acute pancreatitis. World J Emerg Surg. 2019;14:27.

12. Wang M, Wei A, Guo Q, Zhang Z, Lu H, Li A, et al. Clinical outcomes of combined necrotizing pancreatitis versus extrapancreatic necrosis alone. Pancreatology. 2016;16:57-65. https://doi.org/10.1016/j.pan.2015.10.010 PMid:26626203

13. Da Costa DW, Boerma D, van Santvoort HC, Horvath KD, Werner J, Carter CR, et al. Staged multidisciplinary step-up management for necrotizing pancreatitis. $\mathrm{Br} J$ Surg. 2014;101:65-79. https://doi.org/10.1002/bjs.9346 PMid:24272964

14. Weitz G, Woitalla J, Wellhöner $P$, Schmidt $K$, Büning J, Klaus F. Detrimental effect of high volume fluid administration in acute pancreatitis-a retrospective analysis of 391 patients. Pancreatology. 2014;14:478-83. https://doi.org/10.1016/j. pan.2014.07.016 PMid:25451185

15. Wu BU, Batech M, Quezada M, Lew D, Fujikawa K, Kung J, et al 
Dynamic measurement of disease activity in acute pancreatitis: The pancreatitis activity scoring system. Am J Gastroenterol. 2017;112:1144-52. https://doi.org/10.1038/ajg.2017.114 PMid:28462914

16. Ermekova M. Use of CT-based scoring system in assessment of pancreatitis severity. Open Access Maced J Med Sci. 2019;7:3997-4003. https://doi.org/10.3889/oamjms.2019.597 PMid:32165941

17. Cucuteanu B, Prelipcean CC, Mihai C, Dranga M, Negru D. Scoring in acute pancreatitis: When imaging is appropriate? Rev Med Chir Soc Med Nat lasi. 2016;120(2):233-8. PMid:27483698

18. Vinnik YS. The diagnostic value of integral scales in assessing the severity of acute pancreatitis and the patient's condition. Bull Russ Acad Med Sci. 2015;1:90-4. PMid:26027276

19. Mounzer R, Langmead CJ, Wu BU, Evans AC, Bishehsari F, Muddana $\mathrm{V}$, et al. Comparison of existing clinical scoring systems to predict persistent organ failure in patients with acute pancreatitis. Gastroenterology. 2012;142:1476-82; quiz e15-6. https://doi.org/10.1053/j.gastro.2012.03.005 PMid:22425589

20. Irshad B, Imran G, Azher K, Jasima J, Ghanshyam G, Mohmad L. Modified computed tomography severity index for evaluation of acute pancreatitis and its correlation with clinical outcome: A tertiary care hospital based observational study. J Clin Diagn Res. 2016;22:6335-44. https://doi.org/10.7860/ $\mathrm{jcdr} / 2015 / 14824.6368$

21. Abdulnasser A, Sven E. Acute pancreatitis: Value and impact of CT severity index. Abdom Imaging. 2008;33:18-20. https://doi. org/10.1007/s00261-007-9315-0

22. Mikó A, Vigh E, Mátrai $P$, Soós $A$, Garami $A$, Balaskó $M$, et al. Computed tomography severity index vs. Other indices in the prediction of severity and mortality in acute pancreatitis: A predictive accuracy meta-analysis. Front Physiol. 2019;10:1002. https://doi.org/10.3389/fphys.2019.01002 PMid:31507427

23. Sharma V, Rana SS, Sharma RK, Kang M, Gupta R, Bhasin DK A study of radiological scoring system evaluating extrapancreatic inflammation with conventional radiological and clinical scores in predicting outcomes in acute pancreatitis. Ann Gastroenterol. 2015;28:399-404.

\section{PMid:26129965}

24. Bollen TL, Singh VK, Maurer R, Repas K, van Es HW, Banks PA et al. A comparative evaluation of radiologic and clinical scoring systems in the early prediction of severity in acute pancreatitis. Am J Gastroenterol. 2012;107:612-9. https://doi.org/10.1038/ ajg.2011.438

PMid:22186977

25. Tee YS, Fang HY, Kuo IM, Lin YS, Huang SF, Yu MC et al. Serial evaluation of the SOFA score is reliable for predicting mortality in acute severe pancreatitis. Medicine (Baltimore). 2018;97(7):e9654. https://doi.org/10.1097/ md.0000000000009654 PMid:29443733

26. Litvin AA, Knyazeva EG, Filatov AA. Current classification CT definitions of acute pancreatitis. Bull Radiol Radiol. 2018;99:3. https://doi.org/10.20862/0042-4676-2018-99-3

27. Mole DJ, Olabi B, Robinson V, Garden OJ, Parks RW. Incidence of individual organ dysfunction in fatal acute pancreatitis: Analysis of 1024 death records. HPB (Oxford). 2009;11:166-70. https://doi.org/10.1111/j.1477-2574.2009.00038.x PMid:19590643

28. Buddingh KT, Koudstaal LG, van Santvoort HC, Besselink MG, Timmer R, Rosman C, et al. Early angiopoietin-2 levels after onset predict the advent of severe pancreatitis, multiple organ failure, and infectious complications in patients with acute pancreatitis. J Am Coll Surg. 2014;218:26-32. https://doi. org/10.1016/j.jamcollsurg.2013.09.021

PMid:24355874

29. Ge N, Xia Q, Yang ZH, Ding QF, Zeng Z. Vascular endothelia injury and apoptosis in rats with severe acute pancreatitis. Gastroenterol Res Pract. 2015;2015:235017. https://doi. org/10.1155/2015/235017 PMid:25688263

30. Zong GQ, Fei Y, Chen J, Liu RM, Xu YF. Effects of selective double portazygous disconnection and devascularization on hemodynamics of the portal venous system. Med Ultrason. 2014;16:291-7. https://doi.org/10.11152/ mu.201.3.2066.164.gqz PMid:25463880

31. Fei $\mathrm{Y}$, Zong GQ, Chen J, Liu RM. Evaluation the value of markers for prediction of portal vein thrombosis after devascularization. Ann Hepatol. 2015;14:856-61. https://doi. org/10.5604/16652681.1171772

32. Chung WS, Lin CL. Comorbid risks of deep vein thrombosis and pulmonary thromboembolism in patients with chronicpancreatitis: A nationwide cohort study. J Thromb Haemost. 2016;14:98-104. https://doi.org/10.1111/jth.13195

33. Kotel'Nikova LP, Plaksin SA, Kudryavtsev PL, Farshatova LI Pulmonary-pleural complications of pancreatitis. Grekov's Bull Surg. 2017;176(3):28-31.

34. Akimov AA, Styazhkina SN, Valinurov AA, Korolev VK, Chazov AA, Matusevich AE. Pleural complications of pancreatitis. Med Pharm J Pulse. 2018;20(3):13-6.

35. Siemiatkowski A, Wereszczynska-Siemiatkowska $U$ Mroczko B, Galar M, Maziewski T. Circulating endothelial mediators in human pancreatitis-associated lung injury. Eur $\mathrm{J}$ Gastroenterol Hepatol. 2015;27:728-34. https://doi.org/10.1097/ meg. 0000000000000338 PMid:25923947

36. Schepers NJ, Bakker OJ, Besselink MG, Bollen TL, Dijkgraaf MG, van Eijck $\mathrm{CH}$, et al. Early biliary decompression versus conservative treatment in acute biliary pancreatitis (APEC trial): Study protocol for a randomized controlled trial. Trials. 2016;17:5. https://doi.org/10.1186/isrctn97372133 PMid:26729193

37. Butte JM, Hameed M, Ball CG. Hepato-pancreato-biliary emergencies for the acute care surgeon: etiology, diagnosis and treatment. World J Emerg Surg. 2015;10:13. https://doi. org/10.1186/s13017-015-0004-y PMid:25767562

38. Teleuov MK, Uderbaev NN, Almambetov AG, Sergaziev SB, Nauryzov NN. Acute gastrointestinal bleeding in pancreatitis. Med Ecol. 2010;54(1):52-5.

39. Vashetko RV, llyina VA, Kremnev KS, Boroday EA, Ermolaeva MM. Morphofunctional changes in the organs of the gastrointestinal tract and their role in the pathogenesis of the development of multiple organ failure in acute pancreatitis. Ambulance. 2015;2:49-52.

40. Wu LM, Sankaran SJ, Plank LD, Windsor JA, Petrov MS. Meta-analysis of gut barrier dysfunction in patients with acute pancreatitis. $\mathrm{Br}$ J Surg. 2014;101:1644-56. https://doi. org/10.1002/bjs.9665

41. Doi K, Nishida O, Shigematsu T, Sadahiro T, Itami N, Iseki K, et al. The Japanese clinical practice guideline for acute kidney injury 2016. Clin Exp Nephrol. 2018;22:985-1045. https://doi. org/10.1007/s10157-018-1600-4

PMid:30039479

42. Aycock RD, Westafer LM, Boxen JL, Majlesi N, Schoenfeld EM, 
Bannuru RR. Acute kidney injury after computed tomography: A meta-analysis. Ann Emerg Med. 2018;71:44-53. https://doi. org/10.1016/j.annemergmed.2017.06.041

PMid:28811122

43. Sporek $M$, Dumnicka $P$, Gala-Błądzińska A, Ceranowicz $P$, Warzecha Z, Dembiński A, et al. Angiopoietin-2 is an early indicator of acute pancreatic-renal syndrome in patients with acute pancreatitis. Mediat Inflamm. 2016;2016:5780903. https:// doi.org/10.1155/2016/5780903

PMid:27022209

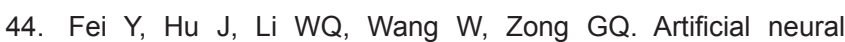
networks predict the incidence of portosplenomesenteric venous thrombosis in patients with acute pancreatitis. J Thromb Haemost. 2017;15:439-45. https://doi.org/10.1111/jth.13588

45. Harris S, Nadkarni NA, Naina HV, Vege SS. Splanchnic vein thrombosis in acute pancreatitis: A single-center experience. Pancreas. 2013;42:1251-4. https://doi.org/10.1097/ mpa.0b013e3182968ff5

PMid:24152951

46. Toqué L, Hamy A, Hamel JF, Cesbron E, Hulo P, Robert S, et al. Predictive factors of splanchnic vein thrombosis in acute pancreatitis: A 6-year single-center experience. J Dig Dis. 2015;16:734-40. https://doi.org/10.1111/1751-2980.12298

PMid:26513113 